\title{
Siting Public Electric Vehicle Charging Stations in Beijing using Big-Data Informed Travel Patterns of the Taxi Fleet
}

\author{
Hua Cai ${ }^{1,2}$, Xiaoping $\mathrm{Jia}^{3}$, Anthony S.F. Chiu ${ }^{4}$, Xiaojun $\mathrm{Hu}^{5}$, Ming $\mathrm{Xu}^{1,2^{*}}$
}

1. School of Natural Resources and Environment, University of Michigan, Ann Arbor, Michigan 481091041, United States

2. Department of Civil and Environmental Engineering, University of Michigan, Ann Arbor, Michigan 48109-2125, United States

3. School of Environmental and Safety Engineering, Qingdao University of Science \& Technology, Qingdao, China

4. Department of Industrial Engineering, De La Salle University, Manila, Philippines

5. Energy Research Institute, Shanghai Jiao Tong University, Shanghai, China

* Corresponding author, Address: 3006 Dana, 440 Church Street, Ann Arbor, MI 48109; Email: mingxu@umich.edu; Tel: +1-734-763-8644; Fax: +1-734-936-2195

\section{Abstract}

Charging infrastructure is critical to the development of electric vehicle (EV) system. While many countries have implemented great policy efforts to promote EVs, how to build charging infrastructure to maximize overall travel electrification given how people travel has not been well studied. Mismatch of demand and infrastructure can lead to under-utilized charging stations, wasting public resources. Estimating charging demand has been challenging due to lack of realistic vehicle travel data. Public charging is different from refueling from two aspects: required time and home-charging possibility. As a result, traditional approaches for refueling demand estimation (e.g. traffic flow and vehicle ownership density) do not necessarily represent public charging demand. This research uses large-scale trajectory data of 11,880 taxis in Beijing as a case study to evaluate how travel patterns mined from big-data can inform public charging infrastructure development. Although this study assumes charging stations to be dedicated to a fleet of PHEV taxis which may not fully represent the real-world situation, the methodological framework can be used to analyze private vehicle trajectory data as well to improve our understanding of charging demand for electrified private fleet. Our results show that 1) collective vehicle parking "hotspots" are good indicators for charging demand; 2) charging stations sited using travel patterns can improve electrification rate and reduce gasoline consumption; 3) with current grid mix, emissions of $\mathrm{CO}_{2}, \mathrm{PM}, \mathrm{SO}_{2}$, and $\mathrm{NO}_{x}$ will increase with taxi electrification; and 4) power demand for public taxi charging has peak load around noon, overlapping with Beijing's summer peak power.

Keywords: Electric vehicle, charging stations, travel pattern, GPS data, transportation emission, grid impact 


\section{Introduction}

2 Greenhouse gas (GHG) emissions and air pollutions generated from fossil fuel-based road transportation have received ever greater attention in recent years, especially in large, dense cities. Electric vehicles (EVs), which include plug-in hybrid electric vehicles (PHEVs) and battery electric vehicles (BEVs), are considered promising alternatives to replace internal combustion engine (ICE) vehicles to reduce energy dependence, mitigate GHG emissions, and improve air quality in urban areas. As part of the efforts to increase urban sustainability, many countries have set goals for electric vehicle adoption(Skerlos and Winebrake, 2010). China hopes to have 500,000 hybrid and electric vehicles on the road by 2015 and five million by 2020 (Murphy and Chiu, 2014). To promote the adoption of electric vehicles, governments in many countries have made significant investment to subsidize EV manufacturers and buyers, build charging stations and posts, and offer tax breaks and other non-monetary incentives (e.g., access to HOV lanes) (Ministry of Finance, 2013; Nilsson et al., 2012; Zheng et al., 2012).

Charging infrastructure is critical to the development of the electric vehicle system (Egbue and Long, 2012). Low availability of charging infrastructure could hinder EV adoption, which could then in turn reduce incentives to invest in charging infrastructure development. Although construction of charging stations has been moving forward in many cities, few research has been done to study where should charging infrastructure be built to maximize overall travel electrification given how people travel. Mismatch of charging demand and charging infrastructure can lead to under-utilized charging stations which is a waste of public resources (CRIENGLISH, 2014).

However, estimating charging demand, especially public charging demand, is a difficult task due to lack of realistic travel pattern data (Zhang et al., 2013). Previous studies use road traffic density (Ip et al., 2010), distribution of gas stations (Liu, 2012), and vehicle ownership data (Frade et al., 2011; Li et al., 2011; Sadeghi-Barzani et al., 2014) as proxy for charging demand. Unlike gasoline or hydrogen fueling which only takes a few minutes, the charging process is normally much longer and could take up to hours. As a result, charging is more likely to happen at the end of a trip rather than in the middle of a trip. Furthermore, in addition of charging vehicles at public charging stations, EV owners can also have the option to charge at home. Therefore, traffic flow volume or vehicle ownership density does not necessarily represent demand for public charging infrastructure. Realizing the importance of charging opportunity at the trip destinations, trips simulated with origin-destination pairs are also used to study charging demand (He et al., 2013; Namdeo et al., 2014; Sweda and Klabjan, 2011; Xi et al., 2013) but simulated travel patterns might be different from the real ones. Household travel surveys can provide detailed trip and parking information for surveyed individuals (Chen et al., 2013), but each individual is only surveyed for a limited duration (e.g., a day or two) which may not be representative. Recent attempts to use real world travel data to study charging infrastructure planning is yet constrained by the limited data sample size of private vehicles (Dong et al., 2014). Due to sampling cost and privacy concerns, sample size of private vehicles is usually in the hundreds. Because public charging demand is an emergent property of heterogeneous individual travel patterns, it is hard to draw conclusions at the fleet or city level with data whose sample size is several magnitudes lower than the fleet population. Fortunately, increasing amount of large-scale travel trajectory data of public fleets have been made available by the recent development of information and communication technologies, which brings 
unprecedented opportunity to better understand how charging infrastructures can be better planned to match real world charging needs. Although results concluded based on the public fleet analysis may not be directly applied to private vehicles, methods developed for public fleets can be directly applied to private vehicles with similar travel trajectory data.

Using Beijing as a case study, this research examines a large-scale data set containing 11,880 taxis in Beijing for a month to study the impact of travel patterns on public charging infrastructure needs. Public fleets (i.e., taxis and buses) are likely early adopters for electric vehicles (Krieger et al., 2012). Beijing aims to put 100,000 electric vehicles on roads by 2015 and build 466 charging stations to support these vehicles (Qi, 2011). Results of this research can provide policy guidance for early stage charging infrastructure development in Beijing. In addition, this study demonstrates the benefit of using largescale individual-based trajectory data (big data) to inform charging infrastructure development. Although this study only includes data from one type of fleet in a specific city, the method and framework developed are readily applicable to other cities when similar data become available.

\section{Data and Method}

There are two major views regarding to the integration of public charging infrastructure into a city: gasstation-based and parking-lot-based, each with its own merits and disadvantages. Gas-station-based charging stations fit existing consumer habit of vehicle refueling and can help reduce "range anxiety". In addition, in long term, while EVs gradually replace ICE vehicles, the increasing charging service can balance the decreasing refueling service at the gas stations and maintain efficient utilization of public infrastructure resources (Wang et al., 2010). However, it is unrealistic to expect drivers to wait around gas stations if the charging takes hours. Parking-lot-based charging stations are more ideal for long duration public charging because it makes charging an add-on activity of a trip (e.g. work, shopping, etc.) and does not require extra time. However, in order to charge at the parking-lot-based charging stations, EV drivers often have to pay for parking fees which could be more expensive than the electricity cost of the charging itself. Because taxis do not normally park for an extensive amount of time during the day (drivers will lose income) and drivers will avoid paying unnecessary parking fees, this research focuses on the gas-station-based public charging stations.

Figure 1 outlines the model framework used in this research. We first extract taxi stop events from the trajectory data to evaluate public charging opportunities. Collective charging opportunity exists in locations where many taxis choose to stop for a long duration. We then score each existing gas station based on how well it aligns with identified charging opportunity. A non-overlapping set of existing gas stations are then selected based on different criteria (e.g. maximum number of parking events, maximum daily parking time, or average parking time per vehicle) as charging stations. It is notable that the identified charging opportunity is not the same as charging demand. True charging demand depends not only on the parking time and location, but also the state-of-charge (SOC, represents the remaining capacity of the battery relative to the all-electric range) of the battery at the beginning of the parking event. Vehicles can park at a location for a long time but has low charging demand if their SOC is almost one (full battery) when they arrive at that location. To capture the true charging demand, we use trip chains extracted from the trajectory data and the selected charging stations to simulate PHEV adoption 
and charging. We assumed PHEV instead of BEV in this study for taxi electrification to allow drivers to finish trips that exceed the battery range on gasoline. The fleet level electrification rate, environmental impacts, and power load profile can then be obtained. Data and model details are described in the subsections below.

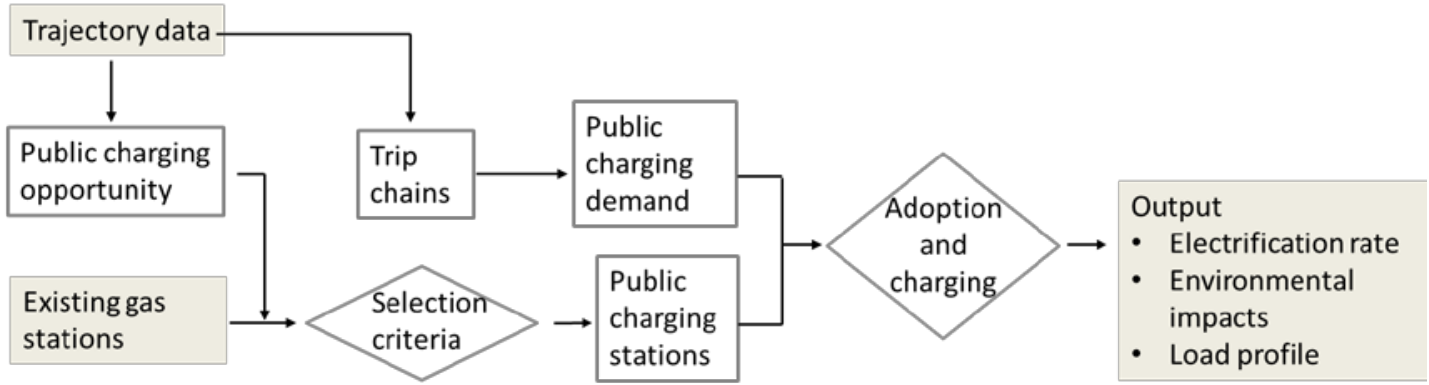

Figure 1. Model framework

\subsection{Background about Beijing Taxis}

Currently there are approximately 66,000 taxis in Beijing (Huo et al., 2012; Zheng et al., 2011). Taxis generally do not work for a dispatch center. Instead, they mainly provide hail service, which means that taxis cruise along the streets and look for clients who signal their needs for taxi services. Drivers possess the vehicle 24/7 and normally park it where they live when off work. These properties make Beijing taxis share some characteristics with private vehicles (e.g. park at home at night and routine trips leaving and returning home). Although some taxis may have multiple shifts (two or more drivers drive the same vehicle in turns), the majority of the taxis only have one dedicated driver (single shift) (Guo et al., 2013). Approximately $79.8 \%$ of the taxis analyzed in this study have average dwell time of at least five hours per day.

\subsection{Data}

After cleanup, the data set used in this study contains continuous trajectory data of 11880 taxis (18\% of the fleet) in Beijing over a period of three weeks (March 2 to 25, 2009). It includes a total of 255 million data points which covers $3.4 \times 10^{7}$ miles of travel and over 2 million trips. Each data point contains the timestamp up to seconds (when the data is recorded), vehicle ID, and vehicle location at the recorded time (in longitude and latitude). Home locations are identified as the location where taxis consistently park at night. Trip chains are extracted with the threshold of minimum parking for five minutes.

\subsection{Adoption and Charging Simulation}

Taxis will adopt PHEV if the life time cost of PHEV is cheaper than that of ICV. Adopted PHEVs will charge at home when they are parked at home (within 0.1 miles of identified home location). Because utility companies in Beijing currently offer to install free home charging outlets or posts for EV owners, we assumed that home charging is universally available without additional cost. The implications of this assumption on results are discussed in the Sensitivity Analysis section (Section 3.5). When taxis are parked at non-home locations for more than 10 minutes, they will use the parking time to charge if 
there are public charging stations within 1 mile $(1.6 \mathrm{~km})$ of the parked location. The service radius of 1 mile is used in this study to account for limited willingness of taxi drivers to change their behavior to accommodate for charging needs. This service radius is similar to the $2 \mathrm{~km}$ range suggested by (Liu, 2012) but is less than the $5 \mathrm{~km}$ range proposed by Beijing government (ChinaDaily, 2014). Detailed charging algorithm can be found in (Cai and Xu, 2013). Vehicle age is not considered in this model.

\subsection{Model Parameters}

7 Home charging has a voltage and current at 220V and 10A. Public fast charging has power output of $837.5 \mathrm{~kW}$ (Tong, 2014); and public slow charging is at 220V and 32A (State Grid Corporation of China, 9 2010). Charging efficiency is $88 \%$ (Kelly et al., 2012). The all-electric range (AER) of the modeled PHEV is 10100 miles. Unit battery cost is at $\$ 300 / \mathrm{kWh}$. The electricity price is at $\$ 0.078 / \mathrm{kWh}$ while the gasoline 11 price is at $\$ 4.86 /$ gal. Life time of a taxi is eight years. The net present value is calculated with a discount 12 rate of $5 \%$. Fuel cost escalation over time is not considered in this model. Fuel efficiency is $130.35 \mathrm{kWh} /$ mile during electric mode and $35 \mathrm{mile} /$ gal during gasoline mode (DOE, 2013). Current 14 government subsidy for PHEV purchase is $\$ 11,240$ per vehicle ( $\$ 5620$ central government subsidy with additional 1:1 match from the Beijing government) (Ministry of Finance, 2013). For environmental impacts, we use emission factors of $236.7 \mathrm{~g} \mathrm{CO}_{2}$-eq $/ \mathrm{km}$ (Huo et al., 2010), 0.0797g PM $2.5 / \mathrm{km}, 0.1336 \mathrm{~g}$ $\mathrm{PM}_{10} / \mathrm{km}, 11.457 \mathrm{~g} \mathrm{SO}_{2} / \mathrm{km}, 0.5384 \mathrm{~g} \mathrm{NO}_{x} / \mathrm{km}$, and $0.138 \mathrm{~g} \mathrm{CO} / \mathrm{km}(\mathrm{Ji}$ et al., 2011) for distance driven in electricity; and $224.4 \mathrm{~g} \mathrm{CO}_{2}$-eq $/ \mathrm{km}$ (Huo et al., 2010), 0.0045g PM $2.5 / \mathrm{km}, 0.012 \mathrm{~g} \mathrm{PM}_{10} / \mathrm{km}, 0.135 \mathrm{SO}_{2} / \mathrm{km}$, $0.42 \mathrm{~g} \mathrm{NO}_{\times} / \mathrm{km}$, and $1.905 \mathrm{~g} \mathrm{CO} / \mathrm{km}$ (Ji et al., 2011) for distances driven in gasoline. We use $0.47 \mathrm{~kg}$ $\mathrm{CO}_{2} / \mathrm{kWh}$ for $\mathrm{CO}_{2}$ emission from natural gas generated electricity (Cai et al., 2007).

\section{Results and Discussion}

\subsection{Public Charging Opportunity Assessment}

The duration when a taxi is parked at non-home locations (e.g. for the driver to rest, have dinner, or wait for the next client) represents public charging opportunities for this taxi without requiring behavior change from the driver. Therefore, locations near which many taxis choose to park for an extensive amount of time could be potential ideal candidates to build charging infrastructure. This overall charging opportunity can be quantified using "vehicle-hour", where 1 vehicle-hour means the equivalent of one vehicle parks at a location for an hour (or equivalently two vehicles each park for half an hour). The probability density distribution of vehicle-hour shows that while most parking events happen in the city, regional "hotspots" exist for both suburbs (Figure 2a) and inner city (Figure 2b). 
a)

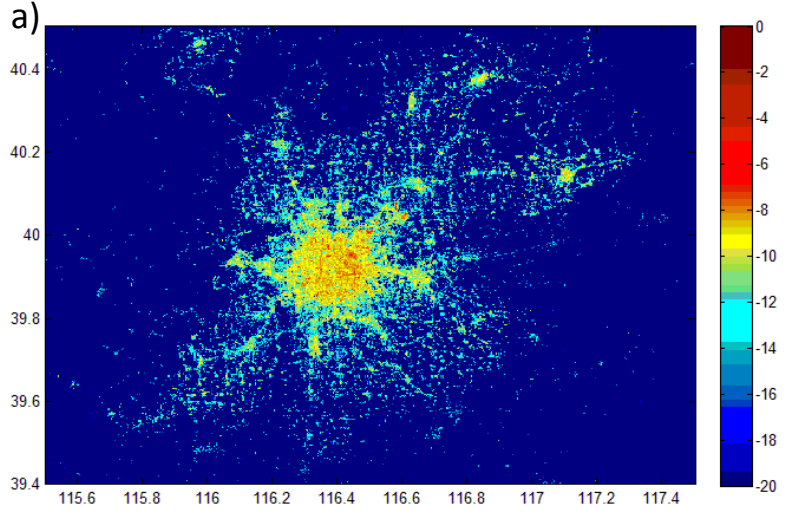

b)

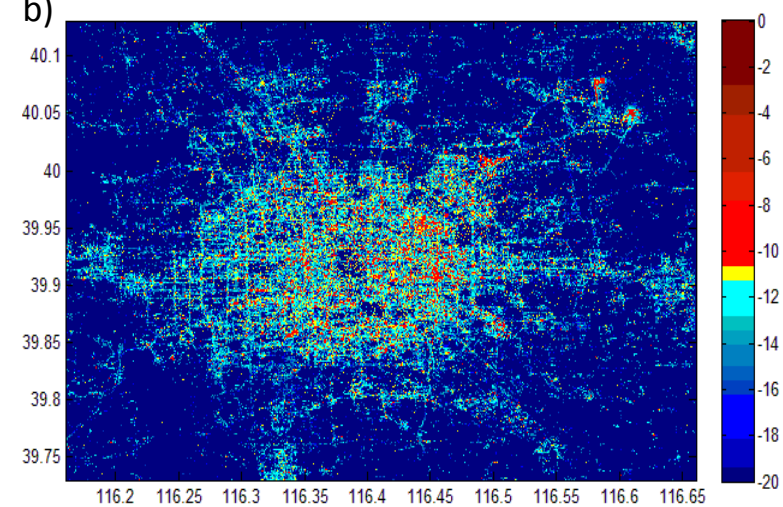

Figure 2. The probability density distribution of vehicle-(parking)-hour for taxis in Beijing; a) shows the entire Beijing administrative region and b) shows zoomed inner city. Both figures are in log scale.

\subsection{Evaluation of Gas-Station-based Charging Stations}

We use three criteria to select existing gas stations for their suitability to be expanded as charging stations: 1 ) the total number of parking events happened in the service range (1 mile) of the gas stations, 2) average vehicle-hour per day within the service range of each gas station, and 3) average vehicle-hour per vehicle within the service range of each gas station. Gas stations with the most parking events (Figure 3a) and daily vehicle-hours (Figure 3b) are concentrated in the center of the city while gas stations with the highest vehicle-hour per vehicle located in the suburb (Figure 3c). This difference shows that charging stations located in the center of the city can provide access to more taxis but may not provide long enough time to achieve full charge due to limited charging time while charging stations located in the suburb may provide longer charging time but will only be able to serve a small number of taxis.

Beijing currently has 40 charging stations/posts built (Figure $3 \mathrm{~d}$ ). We compared the overall mileage electrification rate of the taxi fleet provided by the 40 existing charging stations and 40 gas-stationbased charging stations selected based on each of the three different criteria. Results show that gasstations selected based on either total number of parking events or vehicle-hours per day are more suitable for adding charging capability in order to achieve higher overall electrification rate. Well selected gas-station-based charging stations can improve the overall fleet level electrification rate by $37 \%$ comparing to that of existing charging stations. Home charging alone can electrify $24 \%$ of the miles for the taxi fleet. This rate can be improved to $35 \%$ with existing 40 charging stations and $48 \%$ with the same number of gas-station-based charging stations selected using total number of parking events with fast public charging. The increased electrification rate means that up to 46.4 million gallon of gasoline can be displaced per year by having 40 public charging stations. Average per vehicle parking time is not a good selection criterion when the density of the charging stations is still low. With slow public charging, same trend exists but the overall electrification rates are reduced by $20 \%$ for existing charging stations and by $45 \%$ for gas-station-based charging stations selected with total number of charging events. The 
1 disproportional reduction shows that it is more critical to build fast charging stations at locations that
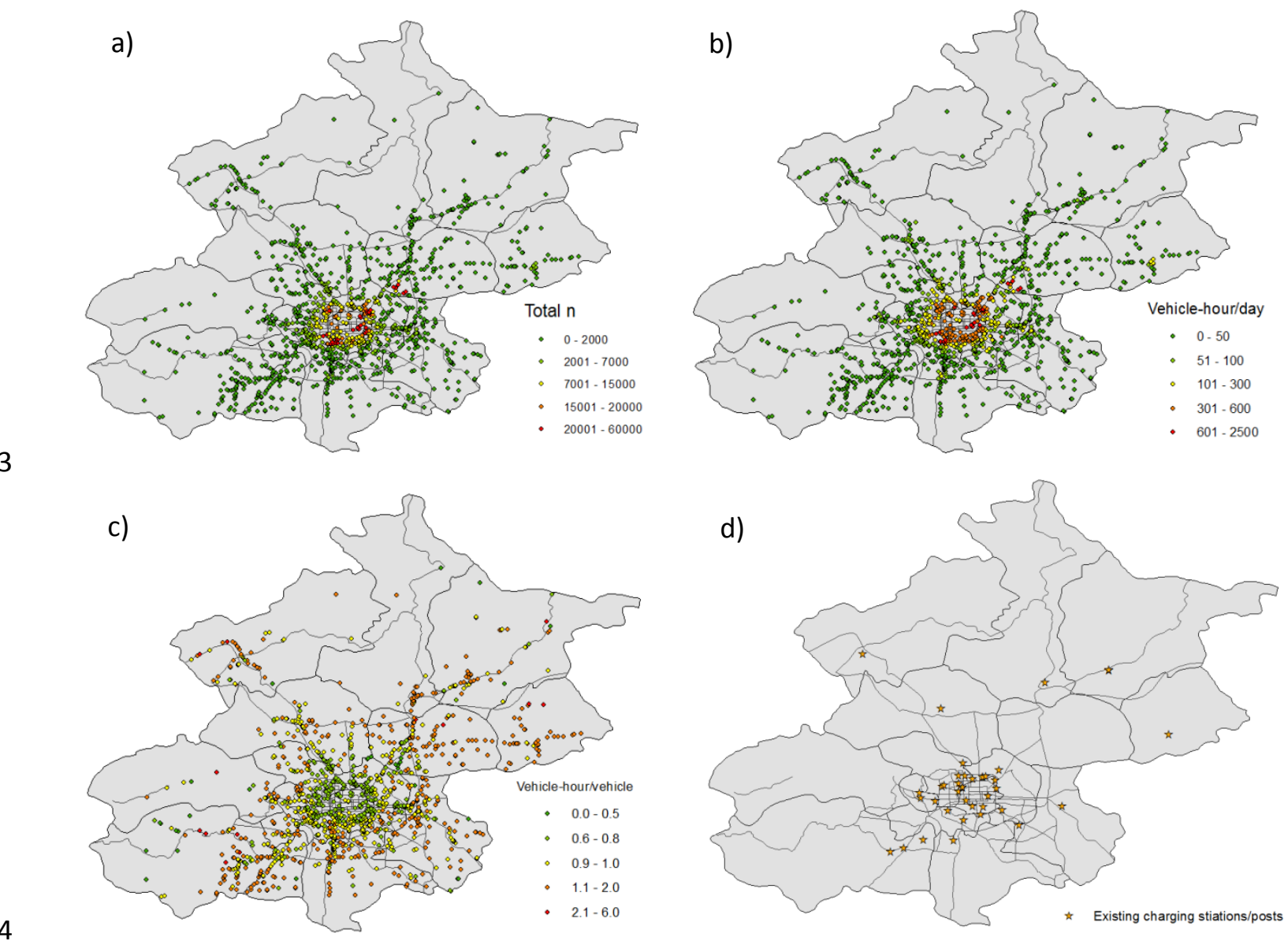

Figure 3. Locations of existing gas stations in Beijing, color coded with a) total number of parking events 6 within service range (1 mile) of the gas station; b) average daily vehicle-hour within service range; and c) parking time per vehicle. d) Location of currently existing charging stations and posts.

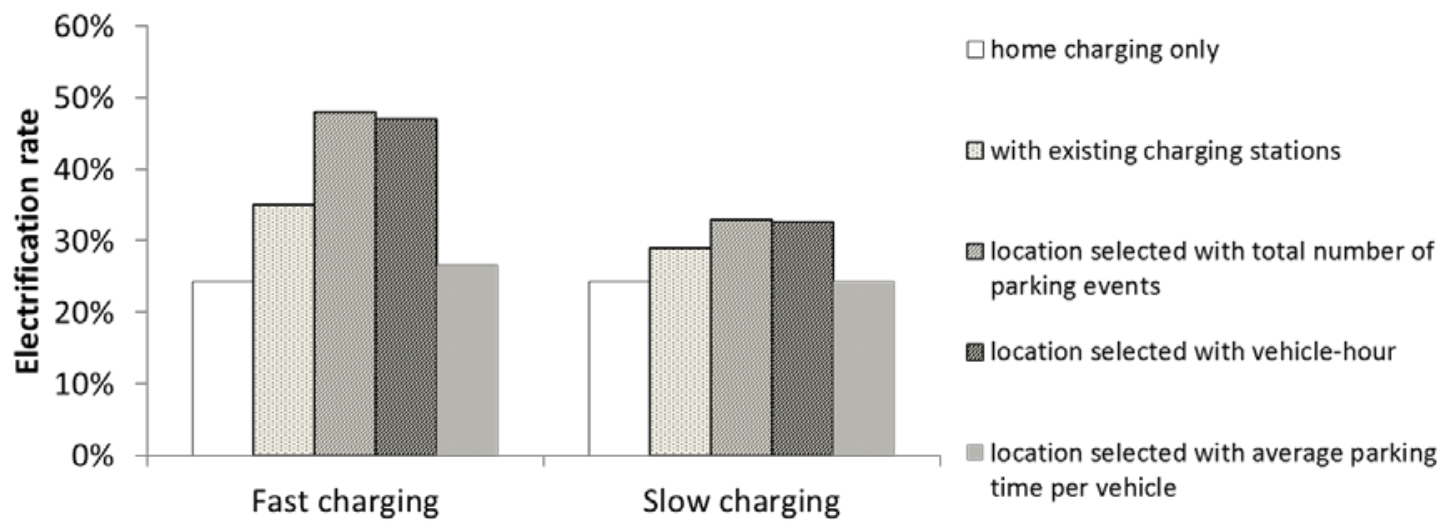


Figure 4. Overall mileage electrification rate of the taxi fleet with different charging scenarios.

3.3 Environmental Impacts

4

In addition of displacing gasoline, higher electrification rate of the taxi fleet will have an impact in emissions of air pollutants as well. Because electricity in the North grid, from where Beijing takes its electricity, is currently generated with $98 \%$ coal (Huo et al., 2010), emissions in $\mathrm{CO}_{2}, \mathrm{PM}_{2.5}, \mathrm{PM}_{10}, \mathrm{SO}_{2}$, and $\mathrm{NO}_{x}$ will increase with higher electrification rate while emission in $\mathrm{CO}$ can be reduced (Table 1). Although the current grid mix makes EVs cause more emission than ICE vehicles in Beijing, it is promising to achieve emission reduction when the grid becomes cleaner (Huo et al., 2010). For example, when the penetration of natural gas reaches more than $10.3 \%$ in the grid, $\mathrm{CO}_{2}$ emission could then be reduced with EV. In addition, relocation of emissions from mobile sources (tailpipes) to concentrated sources (power plants) makes it easier to implement emission reduction and treatment mechanisms (Gong et al., 13 2013).

Table 1. Emission change under different charging scenarios

\begin{tabular}{|c|c|c|c|c|c|c|c|}
\hline \multirow[t]{6}{*}{ Fast charging } & Emission changes (ton/year) & $\mathrm{CO}_{2}$ & $\mathbf{P M}_{2.5}$ & $\mathrm{PM}_{10}$ & $\mathrm{SO}_{2}$ & $\mathrm{NO}_{\mathrm{x}}$ & $\mathrm{CO}$ \\
\hline & Home charging only & 1,063 & 7 & 11 & 979 & 10 & -153 \\
\hline & With existing charging stations & 1,530 & 9 & 15 & 1,409 & 15 & -220 \\
\hline & $\begin{array}{l}\text { Location selected with total } \\
\text { number of parking events }\end{array}$ & 2,103 & 13 & 21 & 1,935 & 20 & -302 \\
\hline & $\begin{array}{l}\text { Location selected with total } \\
\text { vehicle-hour }\end{array}$ & 2,054 & 13 & 20 & 1,891 & 20 & -295 \\
\hline & $\begin{array}{l}\text { Location selected with average } \\
\text { parking time per vehicle }\end{array}$ & 1,161 & 7 & 11 & 1,069 & 11 & -167 \\
\hline \multirow[t]{5}{*}{ Slow charging } & Home charging only & 1,063 & 7 & 11 & 979 & 10 & -153 \\
\hline & With existing charging stations & 1,267 & 8 & 13 & 1,166 & 12 & -182 \\
\hline & $\begin{array}{l}\text { Location selected with total } \\
\text { number of parking events }\end{array}$ & 1,442 & 9 & 14 & 1,328 & 14 & -207 \\
\hline & $\begin{array}{l}\text { Location selected with total } \\
\text { vehicle-hour }\end{array}$ & 1,427 & 9 & 14 & 1,313 & 14 & -205 \\
\hline & $\begin{array}{l}\text { Location selected with average } \\
\text { parking time per vehicle }\end{array}$ & 1,064 & 7 & 11 & 980 & 10 & -153 \\
\hline
\end{tabular}

\subsection{Power Grid Load Impact}

17 Based on the scenario of having 40 charging stations, the average power grid load impact from public charging is presented in Figure 5. The peak demand is around noon time which overlaps with the city's 
day time electricity demand peak (Liu, 2012). Fast public charging results a more significant load shock comparing to slow public charging, which indicates that charging time management techniques need to be implemented with the deployment of fast public charging stations.

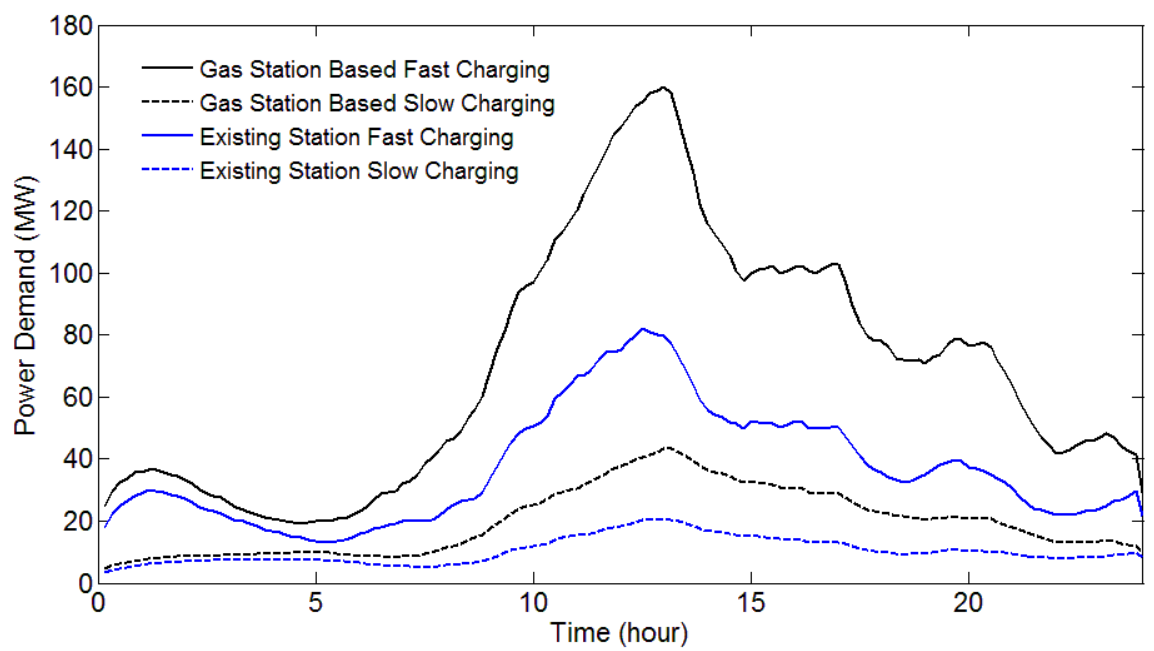

Figure 5. Electricity load profile with 40 public charge stations

\subsection{Sensitivity Analysis}

Key assumptions and parameters made in this study include the availability of home charging, parking time, and battery range. This section discusses how these assumptions and parameters affect the results. Details of the sensitivity analysis are provided in the Supplemental Information.

We assume that home charging is available for all taxis. Among all parking events during a day, home parking is usually the longest and represents important charging opportunities. While it is important to capture these charging opportunities at home, significant barriers (e.g. requirement of dedicated parking space and accessible residential outlets) still exist to reach universal accessibility (Axsen and Kurani, 2012; Traut et al., 2013). If home charging is not available, the overall electrification rate is reduced for all charging scenarios (Figure SP-1).

Parking time determines how much electricity taxis can charge at each station. When parking time is increased or decreased by $10 \%$, electrification rate increases or decreases by $3-5 \%$ for the fast charging scenario (Figure SP-2a). Slow charging is slightly more sensitive to parking time: electrification rate increases or decreases by $5-6 \%$ in response to $10 \%$ parking time changes (Figure SP-2b). When singleshift taxis convert to double-shift ones, in addition to losing home charge opportunities and increased number of trips, parking time at each park event may also be reduced because drivers may rest less to take advantage of the fixed 12-hour shift time. In an extreme scenario that all taxis have multiple shifts, the overall electrification rate will be lower than those shown in Figure SP-1 for no-home-charging conditions. 
The relationship between electrification rate and battery range is an inversed " $U$ " shaped curve (Figure SP-3), similar to what is observed in Cai and Xu (2013). Battery with larger all-electric range can initially increase the overall electrification rate which soon declines when increased battery cost causes adoption reduction. Electrification rate peaks earlier for slow charging than for fast charging, which means that the benefit of having larger batteries will be constrained by the charging speed.

\subsection{Limitation}

This study demonstrates the benefits of using travel patterns derived from large-scale real-world vehicle trajectory data through data mining to inform public charging infrastructure development. It also proposes an innovative approach to estimate public charging demand. However, due to data availability, this study bears the following limitations.

First, this study assumes that data collected for the 11,880 taxis are representative for the entire taxi fleet which consists of approximately 66,000 taxis. Although we have not observed any specific bias in the data, the representativeness of the spatial distribution and travel patterns of the sampled taxis needs to be further examined when additional datasets become available. In addition, taxi usage could exhibit seasonal variations (e.g. more people may take taxis when it is snowing), which may not be captured by analyzing the particular dataset for three weeks in a March. Data with greater temporal coverage or multiple datasets collected at different time of the year could improve this study.

Additionally, one key assumption made in this research is that PHEV taxis will keep the same travel pattern as ICE taxis. It is possible that PHEV taxis will change travel patterns to drive more on electricity and take advantage of the potential fuel savings. However, currently there is no data available to estimate the change of travel behaviors in response to adoption of EVs and this assumption is commonly made in other studies (Pearre et al., 2011; Tamor et al., 2013).

Lastly, while the methodological framework developed in this study is applicable to other fleets and other cities, conclusions drawn in this study should not be generalized to private vehicles in Beijing or taxi fleets in other cities. This study assumes that charging stations are dedicated to taxis and the charging demand of private vehicles is not considered in the siting process. Travel trajectory data for private vehicles will need to be collected and analyzed if the charging stations are designed to also serve private vehicles. In addition, when evaluating charging station candidates for private vehicles, the parking-lot based approach should be used instead of the gas-station-based approach.

\section{Conclusion}

Using Beijing as a case study, this study examines large-scale taxi trajectory data to study public charging station planning and potential environmental and power grid impacts from electric taxi fleet charging. Our results show that 1 ) public charging opportunities identified using collective vehicle parking events can be used as good indicators for public charging demand; 2) gas-station-based charging stations identified with maximum total number of parking events provide the highest overall electrification rate among scenarios examined in this study; 3 ) comparing to existing charging stations, the same amount of 
gasoline displacement for the taxi fleet of up to 46.4 million gallon per year; 4) with current grid mix, emissions of $\mathrm{CO}_{2}, \mathrm{PM}_{2.5}, \mathrm{PM}_{10}, \mathrm{SO}_{2}$, and $\mathrm{NO}_{x}$ will increase with higher electrification rate while emissions of $\mathrm{CO}$ will decrease; and 5) power demand for public electric taxi charging has peak load around noon time, overlapping with Beijing's summer peak power, which means that charging time management techniques are potentially needed, especially for fast charging stations.

While the selected gas-station-based charging stations can provide higher overall electrification rates comparing to existing ones, it is notable that the charging stations selected in this study are suboptimal. Because the SOC of vehicle battery not only depends on the selection of charging station locations but is also path dependent, more advanced algorithm (e.g. genetic algorithm) is needed to solve for the system optimal. This work can be further expanded to identify the optimal number of charging stations given environmental goals and/or total budget. Other factors worth to include in future model include the impact of different siting strategies on power demand, peak and off-peak electricity price and its impact on charging decisions, and charging station capacity (crowding out effect).

\section{Acknowledgements}

This material is based upon work partially supported by the Department of Energy under Award Number DE-PI0000012 and the University of Michigan/Shanghai Jiao Tong University Research Collaboration. H.C. acknowledges the support of Barbour Scholarship from Rackham Graduate School of the University of Michigan. X.J was partially supported by the National Natural Science Foundation of China under project NO. 21136003. The authors thank Dr. Dong Li from China Academy of Urban Planning and Design for his help in spatial data collection.

\section{References}

Axsen, J., Kurani, K.S., 2012. Who Can Recharge a Plug-in Electric Vehicle at Home? Transportation Research Part D: Transport and Environment 17(5), 349-353.

Cai, H., Xu, M., 2013. Greenhouse Gas Implications of Fleet Electrification Based on Big DataInformed Individual Travel Patterns. Environmental Science \& Technology 47(16), 9035-9043. Cai, W., et al., 2007. Scenario Analysis on Co2 Emissions Reduction Potential in China's Electricity Sector. Energy Policy 35(12), 6445-6456.

Chen, T., et al., 2013. Locating Electric Vehicle Charging Stations. Transportation Research Record: Journal of the Transportation Research Board 2385(1), 28-36. ChinaDaily, 2014. Beijing to Light up 1,000 Car Charging Posts, China Daily. CRIENGLISH, 2014. The Development of Ev Charging Stations in Beijing, In: Zhang, P. (Ed.). DOE, U.S., 2013. New Plug-in Hybrids.

Dong, J., et al., 2014. Charging Infrastructure Planning for Promoting Battery Electric Vehicles: An Activity-Based Approach Using Multiday Travel Data. Transportation Research Part C: Emerging Technologies 38, 44-55.

Egbue, O., Long, S., 2012. Barriers to Widespread Adoption of Electric Vehicles: An Analysis of Consumer Attitudes and Perceptions. Energy Policy 48, 717-729. 
Frade, I., et al., 2011. Optimal Location of Charging Stations for Electric Vehicles in a Neighborhood in Lisbon, Portugal. Transportation Research Record: Journal of the Transportation Research Board 2252(1), 91-98.

Gong, H., et al., 2013. New Energy Vehicles in China: Policies, Demonstration, and Progress. Mitigation and Adaptation Strategies for Global Change 18(2), 207-228.

Guo, C., et al., 2013. Taxi Companies Apeal to Increase the Ratio of Double Shift Taxis, Beijing News. Xin Jing Bao, Beijing.

He, F., et al., 2013. Optimal Deployment of Public Charging Stations for Plug-in Hybrid Electric

Vehicles. Transportation Research Part B: Methodological 47, 87-101.

Huo, H., et al., 2012. Vehicle-Use Intensity in China: Current Status and Future Trend. Energy Policy 43, 6-16.

Huo, H., et al., 2010. Environmental Implication of Electric Vehicles in China. Environmental Science \& Technology 44(13), 4856-4861.

Ip, A., et al., 2010. Optimization for Allocating Bev Recharging Stations in Urban Areas by Using

Hierarchical Clustering, Advanced Information Management and Service (IMS), 2010 6th

International Conference on, pp. 460-465.

Ji, S., et al., 2011. Electric Vehicles in China: Emissions and Health Impacts. Environmental Science \& Technology 46(4), 2018-2024.

Kelly, J.C., et al., 2012. Time-Dependent Plug-in Hybrid Electric Vehicle Charging Based on National Driving Patterns and Demographics. Applied Energy 94, 395-405.

Krieger, A., et al., 2012. Recharging China's Electric Vehicle Aspirations: A Perspective on

Revitalizing China's Electric Vehicle Industry, McKinsey \& Company Report.

Li, Y., et al., 2011. Layout Planning of Electrical Vehicle Charging Stations Based on Genetic

Algorithm, In: Wan, X. (Ed.), Electrical Power Systems and Computers. Springer Berlin Heidelberg, pp. 661-668.

Liu, J., 2012. Electric Vehicle Charging Infrastructure Assignment and Power Grid Impacts

Assessment in Beijing. Energy Policy 51, 544-557.

Ministry of Finance, 2013. Guidance for Continually Promoting New Energy Vehicles. The Central

People's Government of the People's Republic of China (in Chinese).

Murphy, C., Chiu, J., 2014. Electric Cars Get a Needed Jolt in China, The Wall Street Journal.

Namdeo, A., et al., 2014. Spatial Planning of Public Charging Points Using Multi-Dimensional

Analysis of Early Adopters of Electric Vehicles for a City Region. Technological Forecasting and

Social Change (In press).

Nilsson, M., et al., 2012. Paving the Road to Sustainable Transport: Governance and Innovation in

Low-Carbon Vehicles (Book). Routledge

Pearre, N.S., et al., 2011. Electric Vehicles: How Much Range Is Required for a Day's Driving?

Transportation Research Part C: Emerging Technologies 19(6), 1171-1184.

Qi, S., 2011. Electric Vehicles in Beijing Will Face More Charging Stations, People's Daily Online.

Sadeghi-Barzani, P., et al., 2014. Optimal Fast Charging Station Placing and Sizing. Applied Energy

$125,289-299$.

Skerlos, S.J., Winebrake, J.J., 2010. Targeting Plug-in Hybrid Electric Vehicle Policies to Increase

Social Benefits. Energy Policy 38(2), 705-708.

State Grid Corporation of China, 2010. Technical Specification for Electric Vehicle Charging Spot (in Chinese).

Sweda, T., Klabjan, D., 2011. An Agent-Based Decision Support System for Electric Vehicle Charging Infrastructure Deployment, Vehicle Power and Propulsion Conference (VPPC), 2011 IEEE, pp. 1-5.

Tamor, M.A., et al., 2013. A Statistical Approach to Estimating Acceptance of Electric Vehicles and Electrification of Personal Transportation. Transportation Research Part C: Emerging Technologies $26,125-134$. 
1 Tong, S., 2014. Beijing: New Energy Vehicles Have Seperate Quota Starting in Feburary 2014.

2 Xinhua Net.

3 Traut, E.J., et al., 2013. Us Residential Charging Potential for Electric Vehicles. Transportation

$4 \quad$ Research Part D: Transport and Environment 25, 139-145.

5 Wang, H., et al., 2010. A Novel Approach for the Layout of Electric Vehicle Charging Station,

6 Apperceiving Computing and Intelligence Analysis (ICACIA), 2010 International Conference on, pp. 64770.

8 Xi, X., et al., 2013. Simulation-Optimization Model for Location of a Public Electric Vehicle Charging 9 Infrastructure. Transportation Research Part D: Transport and Environment 22, 60-69.

10 Zhang, L., et al., 2013. Evaluation of Charging Infrastructure Requirements and Operating Costs for 11 Plug-in Electric Vehicles. Journal of Power Sources 240, 515-524.

12 Zheng, J., et al., 2012. Strategic Policies and Demonstration Program of Electric Vehicle in China.

13 Transport Policy 19(1), 17-25.

14 Zheng, Y., et al., 2011. Urban Computing with Taxicabs, Proceedings of the 13th international

15 conference on Ubiquitous computing. ACM, Beijing, China, pp. 89-98. 